\title{
HEAT CAPACITIES IN SOME AQUEOUS SOLUTIONS
}

\author{
By Frederick D. Rossini
}

ABSTRACT

The problem of properly evaluating the heat capacities of the constituents of aqueous solutions is discussed, and the methods of calculating, from specific heat data possessing the necessary qualifications, the apparent molal heat capacity of the solute, the partial molal heat capacity of the solute, and the partial molal heat capacity of the $\mathrm{H}_{2} \mathrm{O}$ are given.

These partial molal quantities, evaluated from the specific heat data of Richards, et al., on aqueous solutions of hydrochloric acid, sodium hydroxide, acetic acid, sodium acetate, calcium chloride, barium chloride, citric acid, monosodium dihydrogen citrate, disodium monohydrogen citrate, and sodium citrate are given in tabular and graphic form.

The importance of the results in interpreting the behavior of ions and molecules in aqueous solution and their relation to the Debye-Hückel theory of strong electrolytes are discussed.

\section{CONTENTS}

I. Definitions

II. Introduction

III. Methods of

IV. The data on which the calculations are based

V. The calculated results

VI. Discussion

\section{DEFINITIONS}

In this paper the following symbols and definitions will be used:1,2 $\mathrm{H}_{2} \mathrm{O}$.

$m$ is the molality in moles of solute per $1,000 \mathrm{~g}$ or 55.508 moles of

$C_{P}$ is the heat capacity of a system composed of $1,000 \mathrm{~g}$ of $\mathrm{H}_{2} \mathrm{O}$ and $m$ moles of solute.

$\bar{c}_{P_{2}}$ is the partial molal heat capacity of the solute. It is the change in the heat capacity of a very large amount of solution of a given concentration on the addition of 1 mole of solute, the amount of solution taken being so large that the added solute does not appreciably change the concentration. Or, it is the change in the heat capacity, per mole of solute added, of a small amount of solution on the addition of such a small, but measured, amount of solute that the concentration is not appreciably changed.

$$
\bar{c}_{P_{2}}=\frac{\partial C_{P}}{\partial m}
$$

$\bar{c}_{P_{1}}$ is the partial molal heat capacity of the $\mathrm{H}_{2} \mathrm{O}$ in the solution, defined analogously to $\bar{c}_{P_{2}}$, by substituting in that definition, $\mathrm{H}_{2} \mathrm{O}$ for the word solute. In the following equation, $n_{1}$ is the number of moles of $\mathrm{H}_{2} \mathrm{O}$.

$$
\bar{c}_{P_{1}}=\frac{\partial C_{P}}{\partial n_{1}}
$$

1 Lewis and Randall, Thermodynamics, McGraw-Hill Book Co., New York; 1923.

${ }_{2}^{2}$ Randall and Rossini, J. Am. Chem. Soc., 51, p. 323; 1929. 
The partial molal heat capacity of the $\mathrm{H}_{2} \mathrm{O}$ in a given solution less the molal heat capacity of pure $\mathrm{H}_{2} \mathrm{O}$ at the same temperature is $\bar{c}_{P_{1}}-\bar{c}_{P_{1}}{ }^{\circ}$, the relative partial molal heat capacity of the $\mathrm{H}_{2} \mathrm{O}$.

$\phi_{c}$ is the apparent molal heat capacity of the solute. It is the heat capacity of that amount of solution which contains 1 mole of solute minus the heat capacity of an amount of pure $\mathrm{H}_{2} \mathrm{O}$ equivalent to that in the given solution.

$$
\phi_{c}=\frac{C_{P}-55.508 \bar{c}_{P 1}^{\circ}}{m}
$$

\section{INTRODUCTION}

A study of the heat capacities of the constituents of aqueous solutions of strong and of weak electrolytes serves to throw additional light upon the problem of predicting the behavior of these substances when placed in an environment of water molecules.

In an "ideal" solution of two substances, at a given temperature, each will have, by definition, at all concentrations, the same heat capacity and the same heat content which it possesses in the pure condition in the same physical state. Deviations from this simple principle of additivity of heat capacities will depend upon the intermolecular and electrostatic forces which are brought into play when the two substances mixed together do not form an "ideal" solution. If one of the substances in the pure state is highly associated, then admixture with a second kind of molecules may increase or decrease this association, resulting in a consequent change in the heat capacity of the first substance. If one of the substances when in the solution consists of charged particles, these charges will bring about a marked change in the heat content and the heat capacity of the system, as is the case with ions in water.

With liquid water as the solvent we deal with a substance which in itself shows somewhat abnormal properties, and it is important, in a study of the heat capacities of the constituents of aqueous solutions, that the abnormalities present in the heat capacity of pure water be eliminated in determining the contributing heat capacity of the solute at any given concentration and in determining the difference between the heat capacity of $\mathrm{H}_{2} \mathrm{O}$ in the given solution and the heat capacity of pure $\mathrm{H}_{2} \mathrm{O}$. The properties which we shall study are (1) the partial molal heat capacity of the solute at the given concentration; and (2) the relative partial molal heat capacity of the $\mathrm{H}_{2} \mathrm{O}$; that is, the partial molal heat capacity of $\mathrm{H}_{2} \mathrm{O}$ at the given. concentration less the molal heat capacity of pure $\mathrm{H}_{2} \mathrm{O}$ at the same temperature.

The data resulting from a study of the apparent molal heat capacity of the solute and the partial molal heat capacities of the solute and of the $\mathrm{H}_{2} \mathrm{O}$ in aqueous solutions have an immediate practical convenience. The apparent molal heat capacity of the solute can be used to calculate the heat capacity or specific heat of any given solution without the ambiguity which ordinarily exists, in specific heat data found in the literature, as to the relation of joules to calories or as to the particular kind of calorie which has been used

${ }^{3}$ The superscript zero on any symbol refers to that property at infinite dilution. $\bar{c}_{P_{1}} \circ$ is the heat capacity of 1 mole of pure $\mathrm{H}_{3} \mathrm{O}, \quad \phi_{c}{ }^{\circ}\left(=\bar{c}_{P_{2}}{ }^{\circ}\right)$ is the apparent (or partial) beat capacity of one molecule of the solute in an infinite amount of water multiplied by $\mathrm{N}$, the number of molecules in a mole. 
as the unit of energy. The somewhat muddled state of many of the existing data on the heat capacity or specific heats of aqueous solutions could be avoided entirely by reporting the apparent molal heat capacity of the solute in the water solution for the desired concentrations. This information gives directly the relatively small difference between the heat capacity of a given amount of solution and the heat capacity of an amount of pure $\mathrm{H}_{2} \mathrm{O}$ equivalent to that in the given solution.

Given the two systems:

A $1,000 \mathrm{~g} \mathrm{H}_{2} \mathrm{O}$.

$C_{P_{(A)}}=55.508 \bar{c}_{P_{1}}^{\circ}$
B

$1,000 \mathrm{~g} \mathrm{H}_{2} \mathrm{O}$ plus $m$ moles of solute. $C_{P_{(B)}}=55.508 \bar{c}_{P_{1}}{ }^{\circ}+m \phi_{C}$

The difference in the heat capacity of $A$ and $B$ is:

$$
C_{P_{(B)}}-C_{P_{(A)}}=\Delta C_{P}=m \phi_{C}
$$

$\Delta C_{P}$ is, except for extremely large values of $m$, small compared to $C_{P_{(A)}}$ or $C_{P_{(B)}}$; and may be negative or positive. For most dilute solutions of electrolytes, the value of $\Delta C_{P}$ is less than 0.02 of the value of $C_{P_{(A)}}$. When the desired value for the heat capacity of pure water is chosen, the heat capacity of the given solution can be calculated to as high a degree of precision as the heat capacity of pure water is known. ${ }^{4}$

The heat capacity of a given solution can also be calculated from the relation: ${ }^{5}$

$$
C_{P}=55.508 \bar{c}_{P_{1}}+m \bar{c}_{P_{2}}
$$

The partial molal data also possesses importance in that $\bar{c}_{P_{2}}$ and $\bar{c}_{P_{1}}$ are, respectively, the temperature coefficients of the heat content of 1 mole of solute and of 1 mole of $\mathrm{H}_{2} \mathrm{O}$ in the given solution. One of the immediate uses of $\bar{c}_{P 1}-\bar{c}_{P_{1}}{ }^{\circ}$, the relative partial molal heat capacity of the $\mathrm{H}_{2} \mathrm{O}$, is in the calculation of activity coefficients for substances in water solution at any desired temperature from freezing point data on the same solutions.

In lieu of the calorimetric experiments made expressly to determine the $\Delta C_{P}$ of equation (3), the values of $\bar{c}_{P_{2}}$ and $\bar{c}_{P_{1}}$ can be determined by recourse to specific heat data of high precision. T. W. Richards and his coworkers have determined the total heat capacities or specific heats of many aqueous solutions. These data have been used in this paper to calculate values of $\phi_{c}, \bar{c}_{P_{2}}$, and $\bar{c}_{P_{1}}-\bar{c}_{P_{1}}{ }^{\circ}$ for 10 different substances.

\footnotetext{
${ }^{4}$ In calorimetric determinations of the heat capacity of liquids, and especially of aqueous solutions, it is advantageous to include pure water as one of the liquids studied. The accuracy of the investigator's final results is determined by $(a)$ the precision of his measurements and $(b)$ the accuracy with which his calibrated reference standards reproduce the international standards. Any uncertainty with regard to $(b)$ can be eliminated by reporting the final results in such a form as to eliminate the $(b)$ element. This can be accomplished as follows: If $c_{w}$ is the value found for water and $c_{0}$ the value for some other liquid, then the ratio $\frac{c_{s}}{c_{w}}$ should be given. If, however, $c_{w}-c_{s}$ is less than one-half $c_{w}$, the measurements should be carried out differentially and the ratio $\frac{c_{w}-c_{s}}{c_{w}}$ should be reported. If the liquids measured are all dilute aqueous solutions and $c_{w}-c_{s}$ is known with a materially less accuracy than $c_{w}$, it will suffice to measure and report simply the difference $c_{w}-c_{z}$ or the quantity $\Delta C_{P}$ defined above.

By reporting results in the above form the investigator conserves all of the precision of his technic and his data are at any time convertible into energy units by utilizing the at-the-moment best value for $c_{w}$.

See footnote 1, p. 313.
} 


\section{METHODS OF CALCULATION}

The methods of calculation are, with slight modification, those employed by Randall and Rossini. ${ }^{6}$

If sp. ht. is the heat capacity per gram of solution, then

$$
C_{P}=\text { (sp. ht.) }(1,000+m \text { [molecular weight of solute]) }
$$

When $C_{P}$ is determined in this manner, $\phi_{c}$ can be calculated by equation (2). It is important in this latter calculation that the proper value of $\bar{c}_{P_{1}}{ }^{\circ}$ be used, else serious errors will result.

To determine $\bar{c}_{P_{2}}$, the equation derived by Randall and Rossini ${ }^{6}$ is employed:

$$
\bar{c}_{P_{2}}=\phi_{c}+\frac{1}{2} m^{1 / 2} \frac{d \phi_{c}}{d\left(m^{1 / 2}\right)}
$$

This relation can be proved very simply. A rearrangement of equation (2) gives

$$
C_{P}-55.508 \bar{c}_{P_{1}}{ }^{\circ}=m \phi_{c}
$$

Differentiating wiıh respect to $m$, we have

$$
\frac{d C_{P}}{d m}=\phi_{c}+m \frac{d \phi_{c}}{d m}
$$

Noting that $\frac{d C_{P}}{d m}$ is $\bar{c}_{P_{2}}$, and substituting $2 m^{1 / 2} d\left(m^{1 / 2}\right)$ for $d m$ in the last term on the right, we obtain equation (6) directly.

$\phi_{c}$ is plotted as ordinate against $m^{1 / 2}$ as abscissa, and the value $\bar{c}_{P_{2}}$ for any given value of $m^{1 / 2}$ is equal to the ordinate of the curve at that point plus one-half of the abscissa into the slope of the curve at the given point.

The partial molal heat capacity of the water can be expressed most conveniently in terms of $\bar{c}_{P_{1}}-\bar{c}_{P_{1}}{ }^{\circ}$ as this eliminates any ambiguity which may result if the value of $\bar{c}_{P_{1}}{ }^{\circ}$ is inadvertently omitted from the resulting data of a table giving values of $\bar{c}_{P_{1}}$, or if a different value of $\bar{c}_{P_{1}}{ }^{\circ}$ is desirable.

$\bar{c}_{P_{1}}-\bar{c}_{P_{1}}{ }^{\circ}$ can be obtained from the same plot of $\phi_{c}$ against $m^{1 / 2}$ because

$$
\bar{c}_{P_{1}}-\bar{c}_{P_{1}}{ }^{\circ}=-\frac{m}{55.508}\left(\frac{1}{2} m^{1 / 2} \frac{d \phi_{c}}{d\left(m^{1 / 2}\right)}\right)
$$

The term in parenthesis has already been evaluated for given values of the molality in determining $\bar{c}_{P_{2}}$. There simply remains the multiplication of the value of this term by $\frac{m}{55.508}$ and the value of $\bar{c}_{P_{1}}-\bar{c}^{\circ}{ }_{P_{1}}$ is immediately given. Equation (9) is proved as follows:

Substituting (4) into equation (7) we find ${ }^{7}$

$$
55.508\left(\bar{c}_{P_{1}}-\bar{c}_{P_{1}}{ }^{\circ}\right)=m\left(\phi_{c}-\bar{c}_{P_{2}}\right)
$$


But from equation (6)

$$
\phi_{c}-\bar{c}_{P_{2}}=-\left(\frac{1}{2} m^{1 / 2} \frac{d \phi_{c}}{d\left(m^{1 / 2}\right)}\right)
$$

When (11) is substituted into equation (10), equation (9) results.

\section{THE DATA ON WHICH THE CALCULATIONS ARE BASED}

A calculation of $\phi_{c}$, the apparent molal heat capacity, from specific heat data for dilute solutions subjects those data to a rigorous test of their precision. In the case of strong electrolytes, sufficiently precise data will give values of $\phi_{c}$ which, when plotted against the square root of the molality, fall on a smooth, nearly straight curve, with the deviation of the plotted points from the curve gradually increasing as infinite dilution is approached. This naturally increasing deviation with dilution is due to the fact that while the deviations would be uniform throughout for values of $\Delta C_{P}$ of equation (3), values of $\phi_{c}\left(=\frac{\Delta C_{P}}{m}\right)$ are the ones actually plotted. For specific heat data which do not have a precision as good as 1 in 10,000 a haphazard distribution of values of $\phi_{c}$ for small concentrations will result.

This paper gives results obtained by computing $\phi_{c}$ with equations (5) and (2); plotting $\phi_{c}$ against $m^{1 / 2}$; calculating $\bar{c}_{P_{2}}$ by using equation (6); and determining $\bar{c}_{P_{1}}-\bar{c}_{P_{1}}{ }^{\circ}$ by using equation (9).

The data used in the calculations were taken from the work of the late T. W. Richards and his collaborators. Richards and Hall ${ }^{8}$ measured directly the heat capacities of sodium hydroxide solutions, while Richards and Gucker ${ }^{9}$ obtained specific heat values for solutions of sodium hydroxide, acetic acid, and sodium acetate by measuring heats of dilution at two temperatures. Richards, Mair, and Hall ${ }^{10}$ reported specific heat values for hydrochloric acid solutions by measuring three concentrations directly and determining the heat capacities of the more dilute solutions from the temperature coefficient of the heat of dilution. Richards and Mair, ${ }^{11}$ with the aid of some direct heat capacity measurements by Richards and Gucker, ${ }^{12}$ determined the heat capacities of aqueous solutions of citric acid, monosodium dihydrogen citrate, disodium monohydrogen citrate, and sodium citrate from the temperature coefficient of their heats of dilution. Richards and Dole ${ }^{13}$ determined the heat capacity of calcium chloride and of barium chloride solutions from direct measurements of a concentrated solution of each and from the temperature coefficient of the heat of dilution of the more dilute solutions.

The method employed by Richards, et al., in determining these specific heats can best be explained by considering their procedure in the case of a particular substance, say $\mathrm{CaCl}_{2}$ : The heat capacity of a solution of $\mathrm{CaCl}_{2} .50 \mathrm{H}_{2} \mathrm{O}$ was directly measured at $20^{\circ}$ and at $25^{\circ} \mathrm{C}$. Then the heat of dilution of $\mathrm{CaCl}_{2} .50 \mathrm{H}_{2} \mathrm{O}$ with $50 \mathrm{H}_{2} \mathrm{O}$ was measured at the two temperatures. Since the heat capacities of the factors are known, the temperature coefficient of the heat of dilution can be

\footnotetext{
8 Richards and Hall, J. Am. Chem. Soc., 81, pp. 507, 731; 1929.

9 Richards and Gucker, J. Am. Chem. Soc., 51, p. 712; 1929.

10 Richards, Mair, and Hall, J. Am. Chem. Soc., 51, p. 727; 1929.

11 Richards and Mair, J. Am. Chem. Soc., 51, p. 740; 1929.

12 Richards and uucker, J. Am. Chem. Soc., 47, p. 1876; 1925.

13 Richards and Dole, J. Am. Chem. Soc., 51, p. 794; 1929.
} 
used to calculate the heat capacity of the solution produced, $\mathrm{CaCl}_{2}$.$100 \mathrm{H}_{2} \mathrm{O}$. Then the heat of dilution of $\mathrm{CaCl}_{2} \cdot 100 \mathrm{H}_{2} \mathrm{O}$ with $100 \mathrm{H}_{2} \mathrm{O}$ was measured at the two temperatures; and the procedure was continued down to $\mathrm{CaCl}_{2} \cdot 3200 \mathrm{H}_{2} \mathrm{O}$.

There is a slight danger in basing calculations of $\phi_{c}$ upon indirect measurements of this type, because, in going from the concentrated to the dilute solutions, any small error becomes geometrically progressive in magnitude with increase in dilution. Such an error might

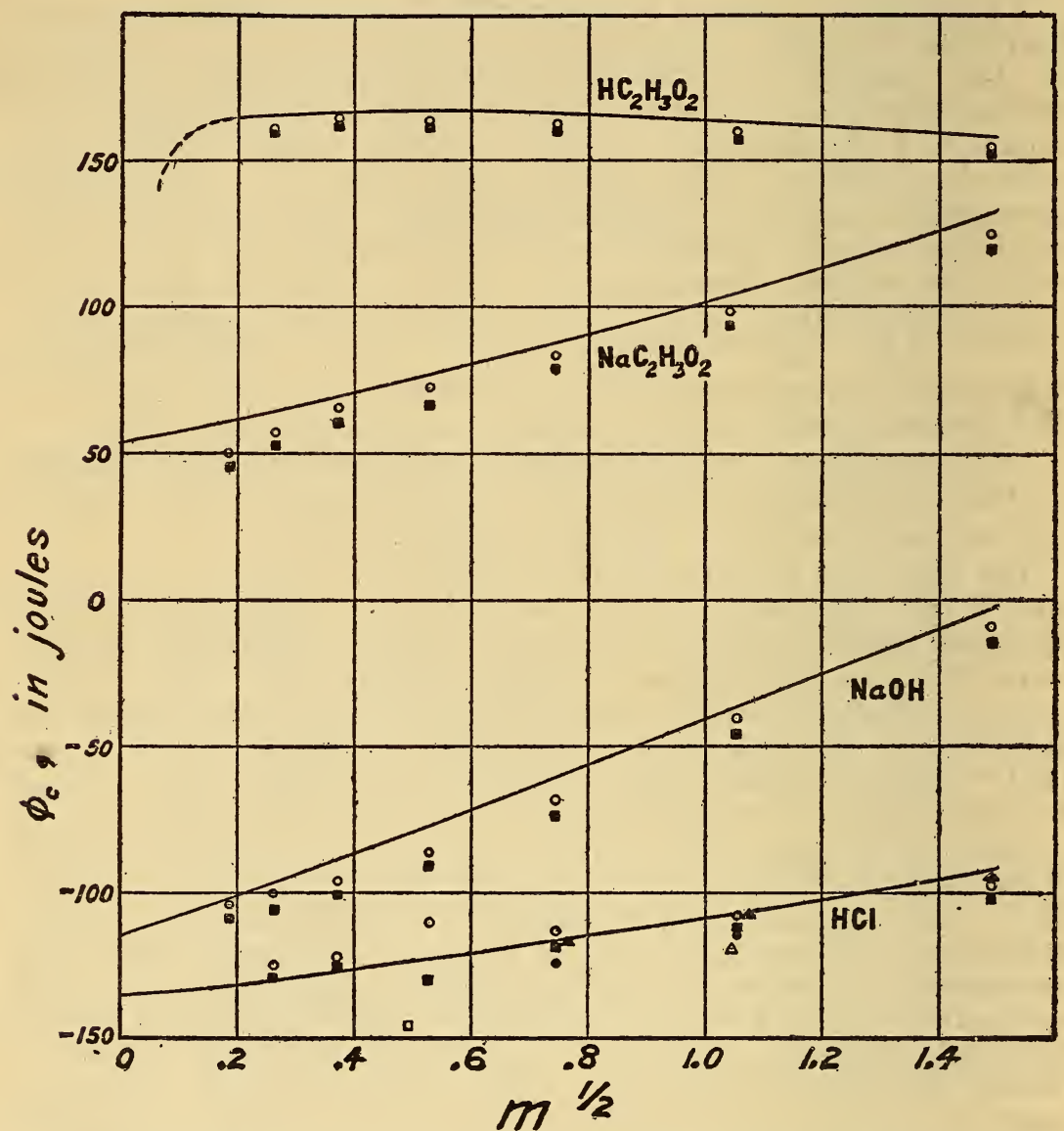

FIGURE 1.-A pparent molal heat capacity, $\phi_{\mathrm{c}}$, plotted against the square root of the molality

The curves are drawn for $25^{\circ} \mathrm{C}$. The experimental data are: 0 , Richards, et al., at $20^{\circ} \mathrm{C}$.; , Richards, et al., at $16^{\circ} \mathrm{C}$; $\square$, Randall and Ramage at $25^{\circ} \mathrm{C}$.; $\triangle$, Wrewsky and Kaigorodoff at $20.5^{\circ} \mathrm{C}$.; $\triangle$, Marignac at $22^{\circ}$ C.;, Thomsen at $18^{\circ} \mathrm{C}$.

not be detected on the plot of $\phi_{c}$ against $m^{172}$ because such a progressive error would result in a raising or lowering of the entire $\phi_{c}$ curve in the dilute region.

From the specific heat data on solutions of $\mathrm{NaOH}, \mathrm{HCl}, \mathrm{HC}_{2} \mathrm{H}_{3} \mathrm{O}_{2}$, and $\mathrm{NaC}_{2} \mathrm{H}_{3} \mathrm{O}_{2}$ values of $\phi_{c}$ at $16^{\circ}$ and $20^{\circ} \mathrm{C}$. were calculated. These are plotted in Figure 1, and the curves are drawn from values of $\phi_{c}$ extrapolated to $25^{\circ} \mathrm{C}$. from the known values at $16^{\circ}$ and $20^{\circ} \mathrm{C}$. 
The data on $\mathrm{H}_{3} \mathrm{C}_{6} \mathrm{H}_{5} \mathrm{O}_{7}, \mathrm{NaH}_{2} \mathrm{C}_{6} \mathrm{H}_{5} \mathrm{O}_{7}, \mathrm{Na}_{2} \mathrm{HC}_{6} \mathrm{H}_{5} \mathrm{O}_{7}$, and $\mathrm{Na}_{3} \mathrm{C}_{6} \mathrm{H}_{5} \mathrm{O}_{7}$ were given for $18^{\circ} \mathrm{C}$, , and the $\phi_{c}$ values for this temperature are plotted in Figure 2.

Figure 3 shows the $\phi_{c}$ values for $\mathrm{CaCl}_{2}$ and $\mathrm{BaCl}_{2}$ at $25^{\circ} \mathrm{C}$.

Wherever possible, values of $\phi_{c}$ in the dilute range calculated from the direct measurements of other investigators were used in locating the $\phi_{c}$ curve. The dilute end of the $\phi_{c}$ curve for $\mathrm{HCl}$, as calculated from the data of Richards, Mair, and Hall, ${ }^{14}$ seemed to be too high. Recourse was had to the data of Marignac, ${ }^{15}$ Wrewsky and Kaigorodoff, ${ }^{16}$ and Randall and Ramage, ${ }^{17}$ on $\mathrm{HCl}$. For $\mathrm{NaC}_{2} \mathrm{H}_{3} \mathrm{O}_{2}$ the curve in the dilute region seemed somewhat low, and the extrapolation to infinite dilution was made by neglecting the values of several of the most dilute solutions.

\section{THE CALCULATED RESULTS}

In Tables 1 and 2 are given the calculated values for $\phi_{c}, \bar{c}_{P_{2}}$, and $\bar{c}_{P_{1}}-\bar{c}_{P_{1}}{ }^{\circ}$. Table 1 gives the results for aqueous solutions of $\mathrm{HCl}$, $\mathrm{HC}_{2} \mathrm{H}_{3} \mathrm{O}_{2}, \mathrm{NaOH}, \mathrm{NaC}_{2} \mathrm{H}_{3} \mathrm{O}_{2}, \mathrm{CaCl}_{2}$, and $\mathrm{BaCl}_{2}$ at $25^{\circ} \mathrm{C}$, while Table 2 gives the calculated data for $\mathrm{H}_{3} \mathrm{C}_{6} \mathrm{H}_{5} \mathrm{O}_{7}, \mathrm{NaH}_{2} \mathrm{C}_{6} \mathrm{H}_{5} \mathrm{O}_{7}, \mathrm{Na}_{2} \mathrm{HC}_{6} \mathrm{H}_{5} \mathrm{O}_{7}$, and $\mathrm{Na}_{3} \mathrm{C}_{6} \mathrm{H}_{5} \mathrm{O}_{7}$ solutions at $18^{\circ} \mathrm{C}$. At the end of Table 1 are given some data on $\mathrm{CaSO}_{4}$, which are explained in Section VI of this paper.

In Figure 4 values of $\bar{c}_{P_{2}}$ at $25^{\circ} \mathrm{C}$, for $\mathrm{HCl}, \mathrm{NaOH}, \mathrm{HC}_{2} \mathrm{H}_{3} \mathrm{O}_{2}$, $\mathrm{NaC}_{2} \mathrm{H}_{3} \mathrm{O}_{2}, \mathrm{CaCl}_{2}$, and $\mathrm{BaCl}_{2}$ are plotted against the square root of the molality. Figure 5 shows values of $\bar{c}_{P_{2}}$ at $18^{\circ} \mathrm{C}$., for $\mathrm{H}_{3} \mathrm{C}_{6} \mathrm{H}_{5} \mathrm{O}_{7}$, $\mathrm{NaH}_{2} \mathrm{C}_{6} \mathrm{H}_{5} \mathrm{O}_{7}, \quad \mathrm{Na}_{2} \mathrm{HC}_{6} \mathrm{H}_{5} \mathrm{O}_{7}$, and $\mathrm{Na}_{3} \mathrm{C}_{6} \mathrm{H}_{5} \mathrm{O}_{7}$. plotted against $m^{172}$. Figure 6 shows values of $\bar{c}_{P_{1}}-\bar{c}_{P_{1}}{ }^{\circ}$ plotted against $\mathrm{m}^{3 / 2}$ for solutions of $\mathrm{HCl}, \mathrm{NaOH}, \mathrm{NaC}_{2} \mathrm{H}_{3} \mathrm{O}_{2}, \mathrm{CaCl}_{2}$, and $\mathrm{BaCl}_{2}$ at $25^{\circ} \mathrm{C}$, and $\mathrm{NaH}_{2} \mathrm{C}_{6} \mathrm{H}_{5} \mathrm{O}_{7}$, $\mathrm{Na}_{2} \mathrm{HC}_{6} \mathrm{H}_{5} \mathrm{O}_{7}$, and $\mathrm{Na}_{3} \mathrm{C}_{6} \mathrm{H}_{5} \mathrm{O}_{7}$ at $18^{\circ} \mathrm{C}$.

\section{DISCUSSION}

In the case of the strong electrolytes, the $\phi_{c}$ against $m^{172}$ curves were extrapolated from a concentration in the neighborhood of 0.02 or 0.04 molal to infinite dilution on the assumption that no abrupt change occurs in the values of the apparent molal heat capacity as the ions pass from this molality to infinite dilution. The measurements of Richards and Dole ${ }^{18}$ on $\mathrm{BaCl}_{2}$ were carried down to 0.0087 molal and showed no abnormality in the measured values other than that due to the natural errors in the experiments. The values of $\bar{c}_{P 2}{ }^{\circ}$ and $\phi_{c}{ }^{\circ}$ so found from these data are probably uncertain to 10 or 20 joules, and in the case of $\mathrm{Na}_{3} \mathrm{C}_{6} \mathrm{H}_{5} \mathrm{O}_{7}$ the uncertainty may be greater than this.

The $\phi_{c}$ curves for the weak electrolytes $\mathrm{HC}_{2} \mathrm{H}_{3} \mathrm{O}_{2}, \mathrm{H}_{3} \mathrm{C}_{6} \mathrm{H}_{5} \mathrm{O}_{7}$, $\mathrm{NaH}_{2} \mathrm{C}_{6} \mathrm{H}_{5} \mathrm{O}_{7}$, and $\mathrm{Na}_{2} \mathrm{HC}_{5} \mathrm{H}_{5} \mathrm{O}_{7}$ were not extrapolated in the above manner as, even in the most dilute solutions measured, the dissociation was very small, The values of $\phi_{c}{ }^{\circ}$ and $\bar{c}_{P_{2}}{ }^{\circ}$ for these substances at infinite dilution were calculated from the values for the sum of the ions. This indicated a very sudden drop in the value of $\phi_{c}$ and $\bar{c}_{P_{2}}$ in the extremely dilute range.

14 See footnote 10, p. 317.

15 Marignac, Oeuvres Complets, 2.

16 Wrewsky and Kaigorodoff, Z. Physik. Chem., 112, p. 83; 1924.

17 Randall and Ramage, J. Am. Chem. Soc., 49, p. 93; 1926.

18 See footnote 13, p. 317 .

$$
88500^{\circ}-30-10
$$




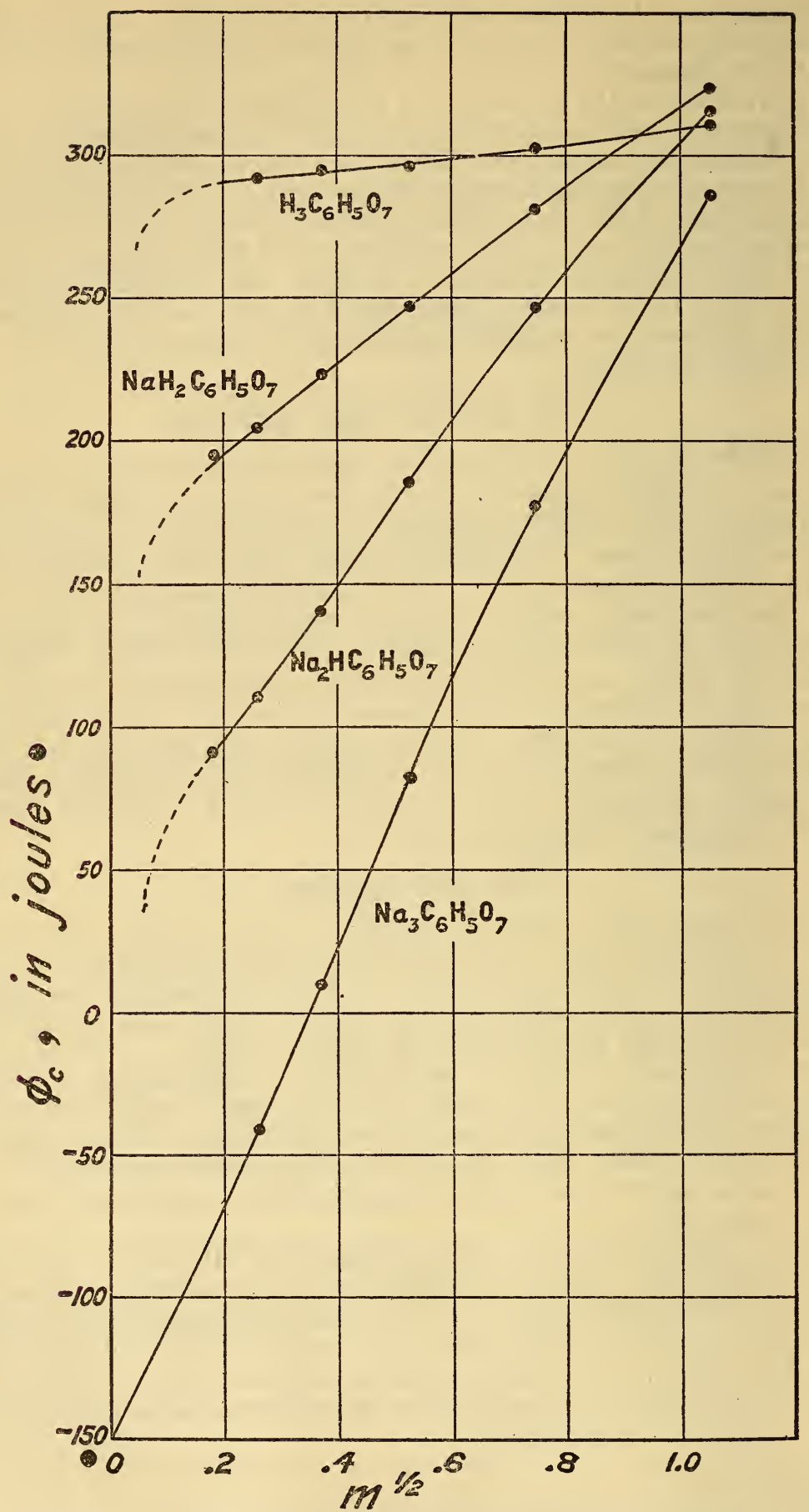

FIgURE 2.-Apparent molal heat capacity, $\phi_{\mathrm{c}}$, plotted against the square root of the molality, at $18^{\circ} \mathrm{C}$.

From the experimental data of Richards and Mair 
From the data of this paper,

$$
\begin{gathered}
\bar{c}_{P}{ }_{(\mathrm{NaOH})}=c_{P}{ }^{\circ}{ }_{\left(\mathrm{Na}^{+}\right)}+\bar{c}_{P}{ }^{\circ}{ }_{\left(\mathrm{OH}^{-}\right)}=-115 \mathrm{j} \\
\bar{c}_{P}^{\circ}{ }_{\left(\mathrm{NaC}_{2} \mathrm{H}_{3} \mathrm{O}_{2}\right)}=\bar{c}_{P}{ }^{\circ}{ }_{\left(\mathrm{Na}^{+}\right)}+\bar{c}_{P}{ }^{\circ}{ }_{\left(\mathrm{C}_{2} \mathrm{H}_{3} \mathrm{O}_{2}-\right)}=54 \mathrm{j}
\end{gathered}
$$

Subtracting these equations, one finds

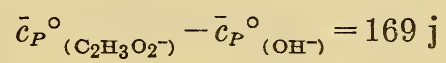

In like manner one can find from the values for $\mathrm{BaCl}_{2}$ and $\mathrm{CaCl}_{2}$,

$$
\bar{c}_{P}^{\circ}{ }_{\left(\mathrm{Ca}^{++}\right)}-\bar{c}_{P}^{\circ}{ }_{\left(\mathrm{Ba}^{++}\right)}=21 \mathrm{j}
$$

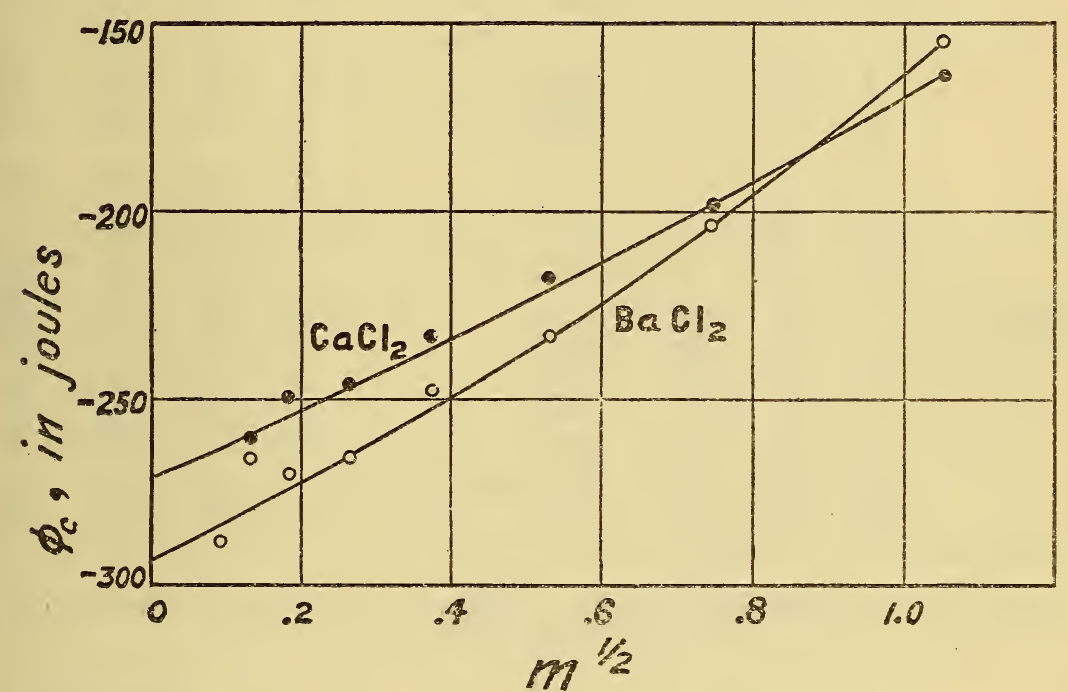

FiguRe 3.-Apparent molal heat capacity, $\phi_{\mathrm{c}}$, plotted against the squore of the molality, at $25^{\circ} \mathrm{C}$.

From the experimental data of Richards and Dole

The values in Table 3 were found in the above manner by combining the data of this paper with those of Randall and Rossini. ${ }^{19}$ This table gives all the known values of $\bar{c}_{P_{2}}{ }^{\circ}$. The evidence corroborates the conclusions of the former work, ${ }^{19}$ in that for simple ions of the same group, $\bar{c}_{P}{ }^{\circ}$ becomes more negative with increase in atomic number (or mass), while for simple ions of the same period, $\bar{c}_{P}{ }^{\circ}$ becomes more negative with increase in atomic number (or charge).

${ }^{10}$ See footnote 2, p. 313. 
TABLE 1.-Heat capacities in aqueous $\mathrm{HCl}, \mathrm{NaOH}, \mathrm{NaC}_{2} \mathrm{H}_{3} \mathrm{O}_{2}, \mathrm{HC}_{2} \mathrm{H}_{3} \mathrm{O}_{2}, \mathrm{CaCl}_{2}$, $\mathrm{BaCl}_{2}, \mathrm{CaSO}_{4}$ solutions at $25^{\circ} \mathrm{C}$.

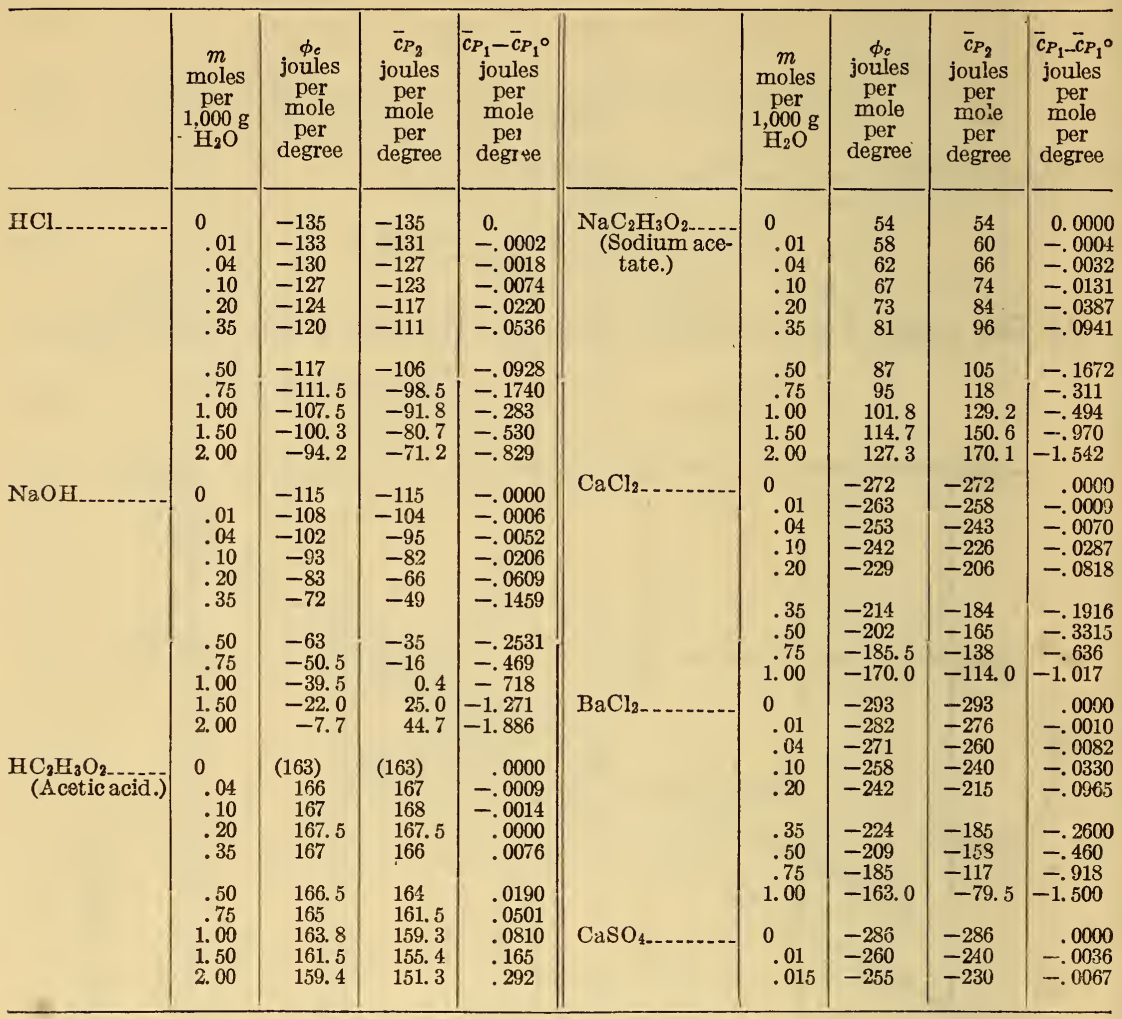

TABLE 2.-Heat capacities in aqueous $\mathrm{H}_{3} \mathrm{C}_{6} \mathrm{H}_{5} \mathrm{O}_{7}, \mathrm{NaH}_{2} \mathrm{C}_{6} \mathrm{H}_{6} \mathrm{O}_{7}, \mathrm{Na}_{2} \mathrm{HC}_{6} \mathrm{H}_{6} \mathrm{O}_{7}$, $\mathrm{Na}_{3} \mathrm{C}_{6} \mathrm{H}_{5} \mathrm{O}_{7}$ solutions at $18^{\circ} \mathrm{C}$.

\begin{tabular}{|c|c|c|c|c|c|c|c|c|c|}
\hline & $\begin{array}{c}m \\
\text { moles } \\
\text { per } \\
1,000 \mathrm{~g} \\
\mathrm{H}_{2} \mathrm{O}\end{array}$ & $\begin{array}{c}\phi_{c} \\
\text { joules } \\
\text { per } \\
\text { mole } \\
\text { per } \\
\text { degree }\end{array}$ & $\begin{array}{c}\bar{c}_{P_{2}} \\
\text { joules } \\
\text { per } \\
\text { mole } \\
\text { per } \\
\text { degree }\end{array}$ & $\begin{array}{c}\bar{c}_{P_{1}}-\bar{c}_{P_{1}}{ }^{\circ} \\
\text { joules } \\
\text { per } \\
\text { mole } \\
\text { per } \\
\text { degree }\end{array}$ & & $\begin{array}{c}m \\
\text { moles } \\
\text { per } \\
1,000 \mathrm{~g} \\
\mathrm{H}_{2} \mathrm{O}\end{array}$ & $\begin{array}{c}\phi_{e} \\
\text { joules } \\
\text { per } \\
\text { mole } \\
\text { per } \\
\text { degree }\end{array}$ & $\begin{array}{c}\bar{c}_{P_{2}} \\
\text { joules } \\
\text { per } \\
\text { mole } \\
\text { per } \\
\text { degree }\end{array}$ & $\begin{array}{c}\bar{c}_{P_{1}}-\bar{c}_{P_{1}}{ }^{\circ} \\
\text { joules } \\
\text { per } \\
\text { mole } \\
\text { per } \\
\text { degree }\end{array}$ \\
\hline \multirow[t]{2}{*}{$\begin{array}{l}\mathrm{H}_{2} \mathrm{C}_{6} \mathrm{H}_{5} \mathrm{O}_{7} \\
\text { (Citric acid.). }\end{array}$} & $\begin{array}{l}0 \\
.04 \\
.10 \\
.20\end{array}$ & $\left(\begin{array}{c}-264 .) \\
292 \\
294 \\
297\end{array}\right.$ & $\left(\begin{array}{c}-264) \\
294 \\
297 \\
301\end{array}\right.$ & $\begin{array}{r}0.0000 \\
-.0012 \\
-.0049 \\
-.0153\end{array}$ & \multirow[t]{2}{*}{$\begin{array}{l}\mathrm{Na}_{2} \mathrm{HC}_{6} \mathrm{H}_{5} \mathrm{O}_{7}- \\
\text { (Disodium } \\
\text { monohy- } \\
\text { drogen ci- } \\
\text { trate). }\end{array}$} & $\begin{array}{l}0 \\
.04 \\
.10 \\
.20\end{array}$ & $\begin{array}{c}(-188) \\
95 \\
126 \\
163\end{array}$ & $\begin{array}{c}(-188) \\
121 \\
169 \\
227\end{array}$ & $\begin{array}{r}.0000 \\
-.0186 \\
-.0775 \\
-.2315\end{array}$ \\
\hline & $\begin{array}{r}.35 \\
.50 \\
.75 \\
1.00\end{array}$ & $\begin{array}{l}299 \\
302 \\
306 \\
310.4\end{array}$ & $\begin{array}{l}306 \\
311 \\
319 \\
326.0\end{array}$ & $\begin{array}{l}-.0416 \\
-.0796 \\
-.1723 \\
-.281\end{array}$ & & $\begin{array}{r}.35 \\
.50 \\
.75 \\
1.00\end{array}$ & $\begin{array}{l}204 \\
236 \\
275 \\
305.5\end{array}$ & $\begin{array}{l}287 \\
329 \\
378 \\
414.5\end{array}$ & $\begin{array}{r}-.525 \\
-.838 \\
-1.389 \\
-1.964\end{array}$ \\
\hline \multirow[t]{2}{*}{$\begin{array}{l}\mathrm{NaH}_{2} \mathrm{C}_{6} \mathrm{H}_{5} \mathrm{O}_{7-} \\
\text { (Monos o o } \\
\text { dium di- } \\
\text { hydrogen } \\
\text { citrate.) }\end{array}$} & $\begin{array}{l}0 \\
.04 \\
.10 \\
.20\end{array}$ & $\begin{array}{c}(-226) \\
195 \\
214 \\
235\end{array}$ & $\left(\begin{array}{c}-226) \\
211 \\
239 \\
272\end{array}\right.$ & $\begin{array}{r}\ldots 0000 \\
-.0113 \\
-.0459 \\
-.1317\end{array}$ & \multirow[t]{2}{*}{$\begin{array}{l}\mathrm{Na}_{3} \mathrm{C}_{6} \mathrm{H}_{5} \mathrm{O}_{7} \\
\text { (Sodium ci- } \\
\text { trate.) }\end{array}$} & $\begin{array}{l}0 \\
.01 \\
.04 \\
.10 \\
.20\end{array}$ & $\begin{array}{r}-150 \\
-110 \\
-66 \\
-15 \\
49\end{array}$ & $\begin{array}{r}-150 \\
-89 \\
-23 \\
58 \\
151\end{array}$ & $\begin{array}{r}.0000 \\
-.0038 \\
-.0307 \\
-.1306 \\
-.360\end{array}$ \\
\hline & $\begin{array}{r}.35 \\
.50 \\
.75 \\
1.00\end{array}$ & $\begin{array}{l}258 \\
276 \\
298.5 \\
316.7\end{array}$ & $\begin{array}{l}305 \\
329 \\
358 \\
387.0\end{array}$ & $\begin{array}{r}-.296 \\
-.478 \\
-.801 \\
-1.231\end{array}$ & & $\begin{array}{r}.35 \\
.50 \\
.75 \\
1.00\end{array}$ & $\begin{array}{l}116 \\
163 \\
223 \\
289.5\end{array}$ & $\begin{array}{l}239 \\
301 \\
380.5 \\
438.8\end{array}$ & $\begin{array}{r}-.790 \\
-1.245 \\
-2.127 \\
-3.050\end{array}$ \\
\hline
\end{tabular}


TABLE 3.-Summary of values of $\bar{c}_{P_{2}}{ }^{\circ}$ at $25^{\circ} C^{1}$

[In joules per mole per degree]

\begin{tabular}{|c|c|c|c|c|c|c|c|}
\hline & $\mathrm{C}_{2} \mathrm{Ei}_{3} \mathrm{O}_{2}-$ & $\mathrm{NO}_{3}^{-}$ & $\mathrm{Cl}^{-}$ & $\mathrm{Br}$ & $\mathrm{I}^{-}$ & $\mathrm{OH}^{-}$ & $\mathrm{SO}_{4}^{--}$ \\
\hline 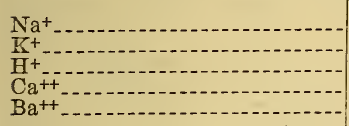 & $\begin{array}{l}54 \\
32 \\
17 \\
21 \\
10\end{array}$ & $\begin{array}{l}-50.0 \\
-72.0 \\
-87 \\
-178 \\
-199\end{array}$ & $\begin{array}{l}-97.5 \\
-119.5 \\
-134 \\
-272 \\
-293\end{array}$ & $\begin{array}{l}-102.5 \\
-124.5 \\
-139 \\
-282 \\
-303\end{array}$ & $\begin{array}{l}-104.0 \\
-126.0 \\
-140 \\
-285 \\
-306\end{array}$ & $\begin{array}{l}-115 \\
-13 i \\
-307 \\
-328\end{array}$ & $\begin{array}{l}-209 \\
-253 \\
-283 \\
-286 \\
-307\end{array}$ \\
\hline
\end{tabular}

1 Compiled from this work and that of Randall and Rossini (see footnote 22, p. 326)

Table 4 gives the $\bar{c}_{P_{2}}{ }^{\circ}$ values for $\mathrm{Na}_{3} \mathrm{C}_{6} \mathrm{H}_{5} \mathrm{O}_{7}$ and for the sum of the ions of the other citrates at $18^{\circ} \mathrm{C}$.

TABLE 4.-Some values of $\bar{c}_{P_{2}}{ }^{\circ}$ at $18^{\circ} \mathrm{C}$

[In joules per mole per degree]

\begin{tabular}{|c|c|}
\hline 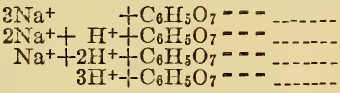 & $\begin{array}{l}-150 \\
-188 \\
-226 \\
-264\end{array}$ \\
\hline
\end{tabular}

The values for $\mathrm{CaSO}_{4}$, which are given at the end of Table 1, were found by taking $\bar{c}_{P_{2}}{ }^{\circ}$ from Table 3 and drawing a curve from this point to $m=0.015$, using the slope predicted by the theoretical equation of Randall and Rossini ${ }^{20}$ corrected by a factor agreeing with the observed deviations from the predicted values. As the solubility of $\mathrm{CaSO}_{4}$ is about 0.015 mole per liter, this gives a precise method of determining the heat capacity of $\mathrm{CaSO}_{4}$ solutions without the use of an extremely precise calorimeter. An error of 20 joules in the value of $\phi_{c}$ for 0.01 molal will make an error of 1 in 20,000 in the value of the heat capacity of 0.01 molal $\mathrm{CaSO}_{4}$ solution. The solubility of $\mathrm{BaSO}_{4}$ is about $10^{-5}$ mole per liter. The data given in Table 3 tell us that the heat capacity of $1,000 \mathrm{~g} \mathrm{H}_{2} \mathrm{O}$ is greater than the heat capacity of $1,000 \mathrm{~g} \mathrm{H}_{2} \mathrm{O}$ plus $10^{-5}$ mole $\mathrm{BaSO}_{4}$ by 0.003 joule, or 1 in $1,400,000$.

The values of $\bar{c}_{P_{2}}$ for weak electrolytes, from the concentrated region down to the molalities where they are still very little ionized, approximates the heat capacity of the pure substance when alone in the liquid state. $\bar{c}_{P_{2}}$ for 1 mole of $\mathrm{HC}_{2} \mathrm{H}_{3} \mathrm{O}_{2}$ is 167 joules at 0.04 molal while the heat capacity of 1 mole of pure $\mathrm{HC}_{2} \mathrm{H}_{3} \mathrm{O}_{2}$ in the liquid state is 123 joules. The difference is probably due to the fact that the acetic acid molecules are less associated in the solution, and, consequently, have a greater heat capacity than in the pure liquid state.

In Figures 4 and 5, the upper extrapolation to infinite dilution, in the curves for the weak electrolytes, is the one that would be mado without additional measurements in the more dilute range or without a knowledge of the values of $\bar{c}_{P}{ }^{\circ}$ for the ions at infinite dilution, and gives approximately the value of $\bar{c}_{P}{ }^{\circ}$ for the undissociated molecule at infinite dilution. The lower broken line in each case shows the extrapolation to the value of $\bar{c}_{P_{2}}{ }^{\circ}$ calculated from the sum of the ions. The smaller the dissociation constant, the steeper is this drop of $\phi_{c}$ and $\bar{c}_{P_{3}}$ in the region adjacent to infinite dilution. The path of this extrapolation is uncertain, without additional meásurements.

\footnotetext{
${ }^{20}$ See footnote 2 , p. 313.
} 
With a precise differential calorimeter of the type used by Randall and Rossini, ${ }^{21}$ satisfactory values of $\phi_{c}$ could be determined at con-

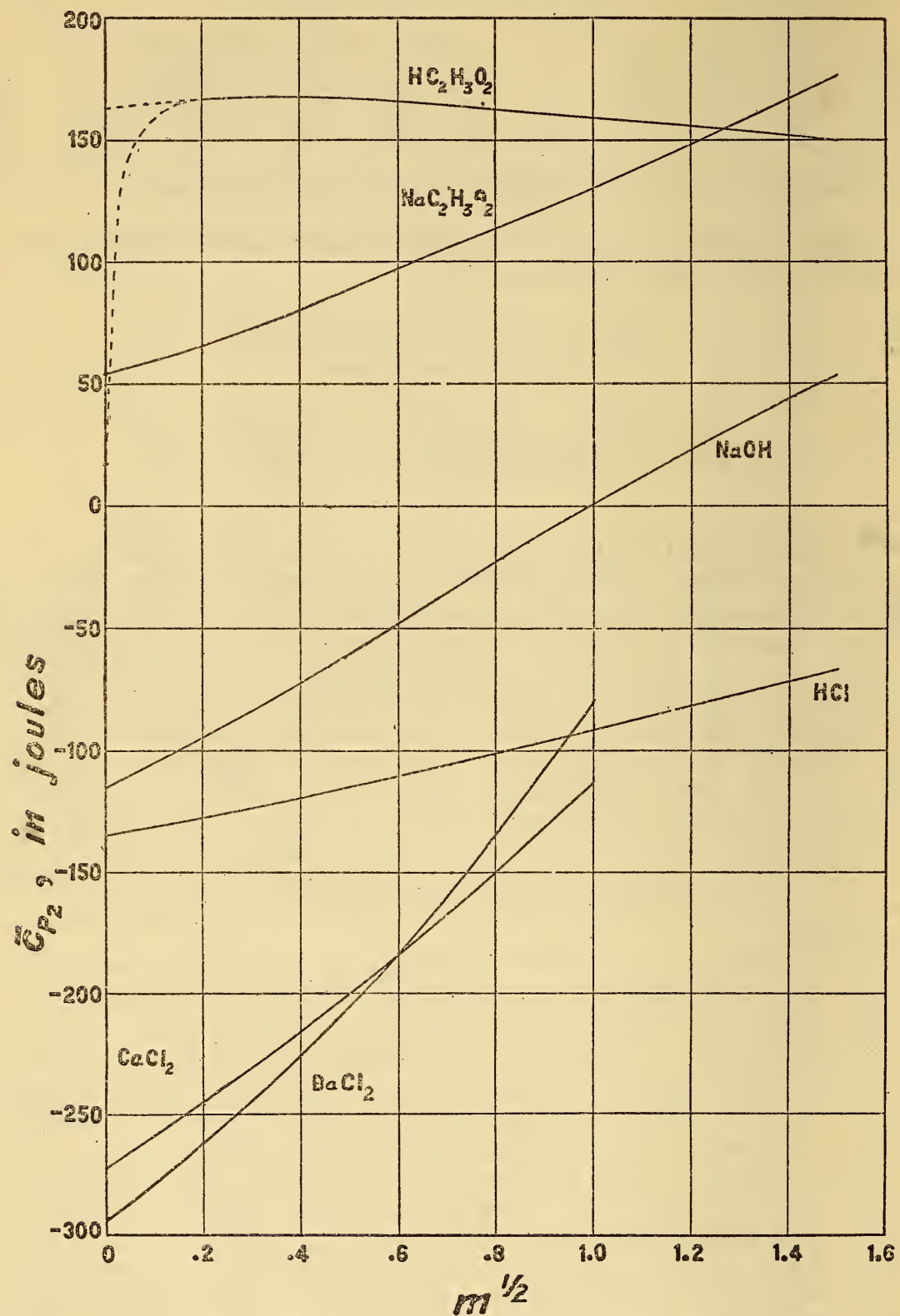

FIGURE 4.-Partial molal heat capacity of the solute, $\bar{c}_{P_{2}}$, plotted against the square root of the molality at $25^{\circ} \mathrm{C}$.

centrations as low as 0.01 or 0.02 molal. If a weak electrolyte were about 50 per cent or more dissociated at this concentration, measurements of $\phi_{c}$ for this electrolyte would show this drop, although the 
change would not be as abrupt as in the case of the very weak electrolytes. Combinations of substances which would show this change, and for which values of $\phi_{c}$ at these low concentrations could be determined, include the sulphates, $\mathrm{Na}_{2} \mathrm{SO}_{4}, \mathrm{NaHSO}_{4}$, and $\mathrm{H}_{2} \mathrm{SO}_{4}$, and the oxalates, $\mathrm{Na}_{2} \mathrm{C}_{2} \mathrm{O}_{4}, \mathrm{NaHC}_{2} \mathrm{O}_{4}$, and $\mathrm{H}_{2} \mathrm{C}_{2} \mathrm{O}_{4}$, Curves for $\mathrm{H}_{2} \mathrm{C}_{2} \mathrm{O}_{4}$ and

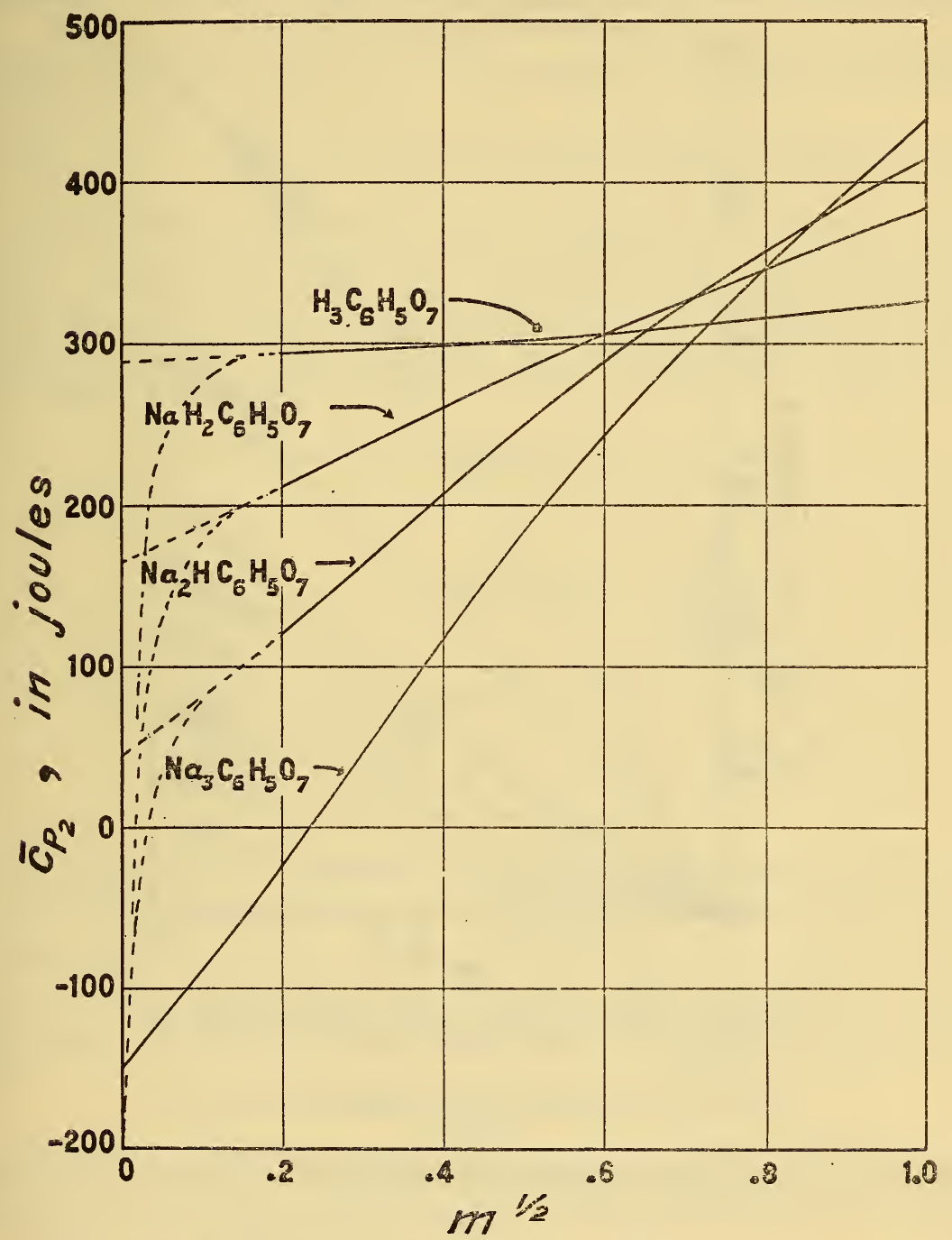

FIGURE 5.-Partial molal heat capacity of the solute, $\bar{c}_{P_{2}}$, plotted against the square root of the molality at $18^{\circ} \mathrm{C}$.

$\mathrm{H}_{2} \mathrm{SO}_{4}$ would definitely show the abrupt increase in the value of $\phi$, and $\bar{c}_{P_{2}}$ with the rapid decrease in ionization as we go from infinite dilution to the dilute region.

The $\phi_{c}$ curve for $\mathrm{Na}_{3} \mathrm{C}_{6} \mathrm{H}_{5} \mathrm{O}_{7}$ was extrapolated to infinite dilution as in the case of strong electrolytes, while the values of $\phi^{\circ}$ and $\bar{c}_{P_{2}}{ }^{\circ}$ for the other citrates were obtained from Tables 3 and 4 . The limiting: slope of the $\bar{c}_{P_{2}}$ curve for $\mathrm{Na}_{3} \mathrm{C}_{6} \mathrm{H}_{5} \mathrm{O}_{7}$ is about 500 (joules against 
$\left.m^{1 / 2}\right)$, while from the theoretical equation for $\bar{c}_{P_{2}}-c_{P_{2}}{ }^{\circ}$ derived by Randall and Rossini ${ }^{22}$ this slope for a unitrivalent salt should be about 370 . In their results on uniunivalent and biunivalent salts, Randall and Rossini also found that the observed slopes were somewhat larger than the predicted ones. Their theoretical equation

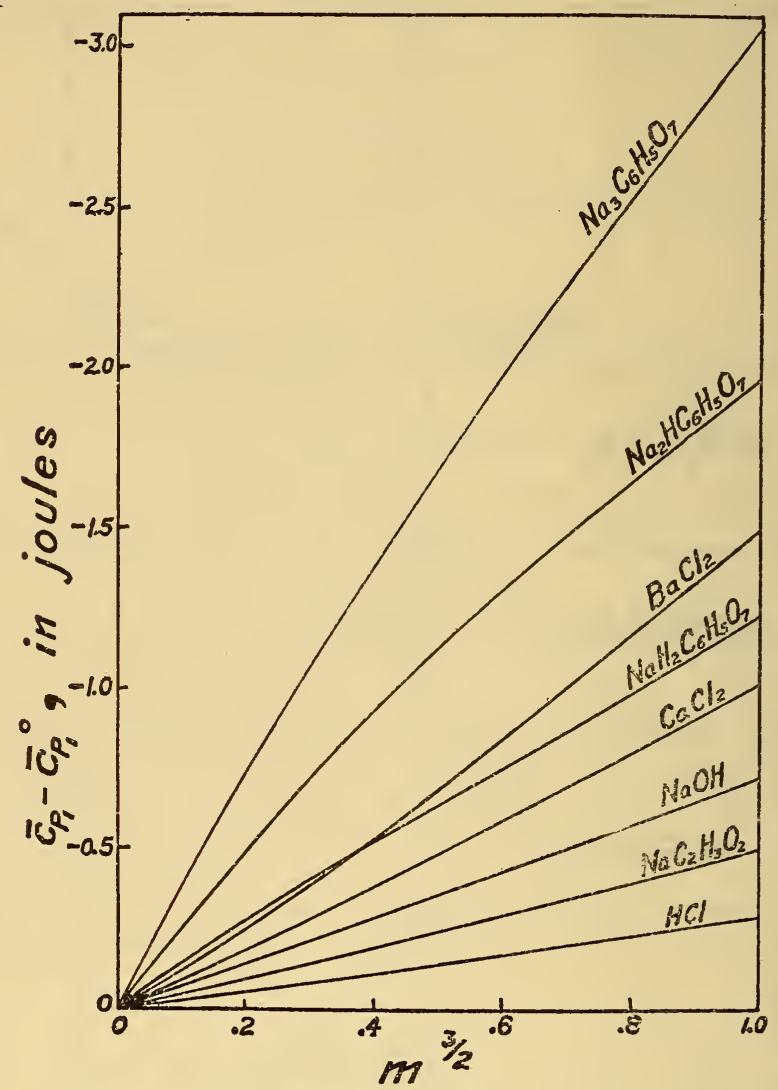

Figure 6.-Relative partial molal heat capacity of $\mathrm{H}_{2} \mathrm{O}, \bar{c}_{P_{1}}-\bar{c}_{P_{1}}{ }^{\circ}$, plotted against the $3 / 2$ power of the molality

All the curves are for $25^{\circ} \mathrm{C}$., except those for the three citrates which are for $18^{\circ} \mathrm{C}$.

derived on the basis of the Debye-Huckel theory of strong electrolytes and evaluated for $25^{\circ} \mathrm{C}$ is:

$$
\bar{c}_{P_{2}}-\bar{c}_{P_{2}}{ }^{\circ}=8.95\left(\Sigma \nu_{i} z_{i}{ }^{2}\right)^{3 / 2} m^{172} \text { (joules per mole per degree) }
$$

Here $\nu_{i}$ is the number of ions of the $i$ th kind furnished by the given molecule and $z_{i}$ is the charge on the $i$ th kind of ions.

The limiting slopes for the $\mathrm{BaCl}_{2}$ and $\mathrm{CaCl}_{2}$ curves of $\bar{c}_{P_{2}}$ against $m^{1 / 2}$ are about the same order of magnitude as the slopes previously observed ${ }^{22}$ for $\mathrm{Na}_{2} \mathrm{SO}_{4}$ and $\mathrm{K}_{2} \mathrm{SO}_{4}$. Equation (16) predicts identical slopes for all these biunivalent or unibivalent electrolytes. 
In Figure 6 are plotted values of $\bar{c}_{P_{1}}-\bar{c}_{P_{1}}{ }^{\circ}$ against $m^{3 / 2}$. It can be shown ${ }^{23}$ that if $\bar{c}_{P_{2}}-\bar{c}_{P_{2}}{ }^{\circ}$ is a linear function of $m^{1 k^{12}}$, then $\bar{c}_{P_{1}}-\bar{c}_{P_{1}}{ }^{\circ}$ is a linear function of $m^{372}$. Starting with the partial molal equation, ${ }^{24}$

$$
m d \bar{c}_{P_{2}}+55.508 d \bar{c}_{P_{1}}=0
$$

substituting the value of $\bar{c}_{P_{2}}$ from equation (16), and integrating (17), one finds ${ }^{25}$ for $25^{\circ} \mathrm{C}$.:

$$
\bar{c}_{P_{1}}-\bar{c}_{P_{1}}{ }^{\circ}=-0.0537\left(\Sigma \nu_{i} z_{i}^{2}\right)^{372} m^{3 / 2} \text { (joules per mole per degree) }
$$

Theoretically, the slopes of $\bar{c}_{P_{1}}-\bar{c}_{P_{1}}{ }^{\circ}$ against $m^{322}$ should in the dilute region be those predicted by equation (18). As in the case of the $\bar{c}_{P_{2}}$ curves, we find the observed slopes to be somewhat greater than the predicted ones, although the curves for electrolytes of the same type occur together and the slopes increase with increase in the value of the factor $\left(\Sigma \nu_{i} z_{i}^{2}\right)^{372}$.

TABLE 5.-Temperature coefficient of $\bar{c}_{P_{2}}$ at $15^{\circ}$ to $25^{\circ} \mathrm{C}$.

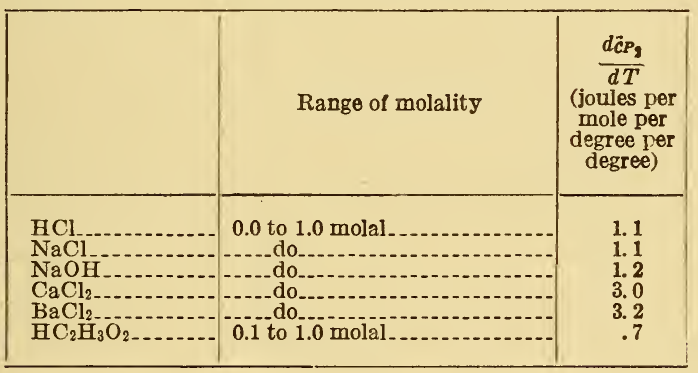

Table 5 gives the temperature coefficient of $\bar{c}_{P_{2}}$ for some of the substances dealt with in this paper. It will be noted that, in the case of the strong electrolytes, the value of $\frac{d \bar{c}_{P_{2}}}{d T}$ is about the same for substances of the same valence type, and that this value increases with increase in the number of ions and with increase in the charge on the ions.

\section{ACKNOWLEDGMENT}

The author wishes to express his gratitude to E. W. Washburn for his helpful advice and criticism of this work.

Washington, September 27, 1929.

${ }^{23}$ See footnote 17, p. 319 .

${ }^{24}$ See footnote 1, p. 313 .

${ }^{25}$ An equation for $\bar{c}_{1}$ was derived by Lange and Messner, Z. Elektrochem., 33, p. 431; 1927. 